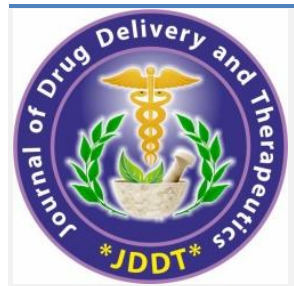

Open Access Full Text Article
Available online on 15.11.2021 at http://jddtonline.info

\section{Journal of Drug Delivery and Therapeutics}

Open Access to Pharmaceutical and Medical Research

Copyright (C) 2021 The Author(s): This is an open-access article distributed under the terms of the CC BY-NC 4.0 which permits unrestricted use, distribution, and reproduction in any medium for non-commercial use provided the original author and source are credited

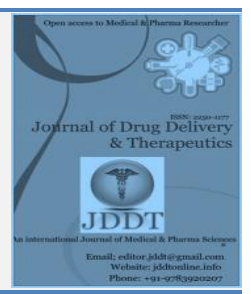

Review Article

\title{
Importance need and benefits of daily Riyazat (Exercise): A Review
}

\author{
Araf Fatma ${ }^{1}$, Aisha Perveen*2, Rubi Anjum ${ }^{3}$ \\ ${ }^{1}$ PG Scholar, Department of Tahaffuzi-wa-Samaji Tibb, School of Unani Medical Education and Research, Jamia Hamdard, India \\ ${ }^{2}$ Assistant Professor, Dept. of Tahaffuzi-wa-Samaji Tibb, School of Unani Medical Education and Research, Jamia Hamdard, India \\ ${ }^{3}$ Professor, Dept. of Tahaffuzi-wa-Samaji Tibb, Ajmal Khan Tibbiya College, AMU, India
}

\section{Article Info:}

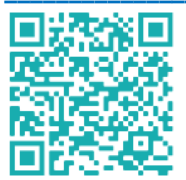

Article History:

Received 19 September 2021

Reviewed 26 October 2021

Accepted 08 November 2021

Published 15 November 2021

\section{Cite this article as:}

Fatma A, Perveen A, Anjum R, Importance need and benefits of daily Riyazat (Exercise): A Review,

Journal of Drug Delivery and Therapeutics. 2021; 11(6):315-318

\begin{abstract}
Riyazat (Exercise) is any deliberately structured and planned bodily movement performed to improve physical fitness, health, and overall wellbeing. It is performed for many reasons like strengthening of tendons, muscles, ligaments, cardiovascular system, maintenance or loss of weight, enhancement of athletic skills, improvement of metabolic functions, to improve mental health by reducing stress, and sometimes merely for enjoyment. Numerous ancient Unani experts, including Galen, Hippocrates, Avicenna, and Rhazes, have written treatises on the advantages of Riyazat. Riyazat is a regimented treatment that prevents the buildup of morbid material and aids in the natural outflow of waste products from the body, hence lowering the risk of acquiring a variety of ailments. Regular riyazat helps to build immunity, avoids and cures a variety of ailments and promotes overall health.
\end{abstract}

Keywords: Riyazat, regimenal therapy, morbid material.

DOI: $h$ ttp://dx.doi.org/10.22270/jddt.v11i6.5119

*Address for Correspondence:

Dr. Aisha Perveen, Assistant Professor, Dept. of Tahaffuzi-wa-Samaji Tibb, School of Unani Medical Education and Research, Jamia Hamdard

\section{Introduction}

Unani medicine is a conventional word for Graeco-Arabic medicine, a kind of traditional medicine that is widely practiced across the Middle East and South Asia. This system of medicine was originated in Greece around 2500 years back and is based on the teachings of great scholars like Hippocrates, Galen, Avicenna (Ibn-e- Sina), Rhazes (AlRazi), Ibn Nafis, and Al-Zahrawi. This medical system is thorough and careful in its approach to different stages of illness and health, providing preventative, curative, and rehabilitative therapy (1). There are several treatment modalities in Unani medicine, one of which is regimenal therapy (Ilaj-bil-tadbeer), which is one of the most widely practiced. In this mode of treatment, certain specialized techniques are used to improve the body's constitution by enhancing the body's defense mechanism and removing waste materials from the body. By adjusting and sustaining Asbaab-e- Sitta Zarooriya, health is maintained by regimented therapy (six essential factors for life). In addition to Hamam (Turkish bath), Hijamah (Cupping), Fasd (Venesection), Huqna (Enema), Riyaazat (Exercise), Ta'leeq (Leaching) and Huqna (Enema), etc., there are many other examples of these regimens. Due to the environmental friendliness of these methods of treatment, many industrialized countries are beginning to recognize and implement them (2). Riyazat (exercise) is a frequently practiced Ilaj-bil-tadbeer regime that improves and maintains physical fitness and promotes a person's general health and well-being. It not only promotes health but also helps avoid certain ailments. In riyazat (exercise), voluntary motions are utilized to eliminate waste elements from a sick individual's body (Tanqiya-e-Mawaad). Riyazat is also used for various purposes, such as weight loss or physical fitness, muscular building, or even for pure pleasure. It aids in the prevention of lifestyle disorders such as type 2 diabetes, obesity, cardiovascular diseases, and hypertension, among others. Riyazat also acts as an anti-anxiety, anti-insomnia, and anti-depressant, as well as aids in self-esteem maintenance. Ancient Greek philosophers developed a set of rules and laws governing the intensity of the workouts. Additionally, they specified the times and circumstances for specific physical exercises (3).

The main objectives of performing Riyazat (exercise) are: (3) (4)

- To relieve from conditions like anxiety, insomnia, and depression.

- It enhances the metabolism of the body. 
- Aids in the elimination of waste materials from the body.

- Helps in toning up the individual organs of the body.

- It strengthens the body as a whole and improves its flexibility.

How do physical activity and fitness contribute to improved health outcomes?

Physical activity (expending more than $2000 \mathrm{kcal}$ [8400 kJ] per week) was associated with an increase in life expectancy of one or two years by the age of 80 , and the advantages remained linear even at lower levels of energy dispersal, according to Paffenbarger and collaborators in their work (5). Further research has connected a weekly average energy expenditure of up to $1000 \mathrm{kcal}(4200 \mathrm{~kJ})$ with a $20-30 \%$ reduction in all-cause death. In recent years, health professionals have recommended a physical workout that burns at least $1000 \mathrm{kcal}$ (4200 kJ) every week, as well as the additional benefits of larger energy expenditures (6).

Perspectives of different old physicians regarding Riyazat (exercise) (7)

The majority of medical historians believe that therapeutic exercises were first popularised in ancient Greece.

Herodicus was a 5th-century BC Greek physician from Selymbria who is known as the "Father of Therapeutic Exercise" because he claimed to have cured his incurable condition with exercise and later established an intricate system of exercises for athletes.

Hippocrates (460-375 BCE), an ancient Greek physician who studied under Herodicus, wrote extensively about the benefits of exercise, such as weight loss, muscle building, and mental health improvement.

Galen, born in $129 \mathrm{AD}$, was a renowned physician, surgeon, and philosopher during the second century of the Roman
Empire. He wrote extensively about exercise, categorizing it by intensity, duration, and frequency.

Rhazes (865AD-925AD) was a Persian philosopher who made significant contributions to the history of medicine. In his work Kitab-ul-Murshid, he discussed the different types of exercise, their appropriate times and uses, as well as preventative steps to take before and after exercise.

Avicenna (980AD-1030AD) elaborated on Riyazat in his renowned book Al Qanoon Fit Tib. He discussed the mechanism of action, the ways and kinds of Riyazat, therapeutic exercise, particular exercises for each organ, as well as the dosage and limit of Riyazat.

\section{Types of Riyazat}

a) Riyazate Haqeeqi/Kulli /Complete exercise e.g. horseriding (8) (9)

b) Riyazate Juziya /Partial exercise e.g. stone lifting (9) (8) (10) (11)

Certain or partial workouts are tied to specific quwa (faculties) and specific organs, such as reading little alphabet through eyes, sobbing is the exercise of children, and angriness is the exercise of those with Barid Mizaj (cold temperament).

\section{Other Types of Riyazat}

A. Riyazate A'arziya/Ghair Iradi (unwillingly): When there is no desire to exercise, it is performed as part of everyday routine occupational activities, such as ironsmithing and washerman (10) (8).

B. Riyazat-e-Zatiya /Khalisa: This exercise is done on purpose to get the advantages. It is further Sub categorized according to its duration, intensity, and modality, among other factors. (10) (8)

\section{Types of Riyazat-e-Zatiya/Khalisa}

\begin{tabular}{|c|c|c|}
\hline \multirow{3}{*}{\multicolumn{2}{|c|}{$\circ$ According to duration }} & $\begin{array}{l}\text { Riyazat-e-qaleela } \\
\text { Short duration exercise (8). }\end{array}$ \\
\hline & & $\begin{array}{l}\text { Riyazat-e-kaseera } \\
\text { Long duration exercise (11) (8). }\end{array}$ \\
\hline & & $\begin{array}{l}\text { Riyazat-e-moatadil } \\
\text { Movements in between Riyazat qaleela, and kaseera (11) (8). }\end{array}$ \\
\hline & According to strength & $\begin{array}{l}\text { Riyazat-e-qawiya/shadeeda } \\
\text { Forceful exercise (11) (8). }\end{array}$ \\
\hline & & $\begin{array}{l}\text { Riyazat-e- zaeefa } \\
\text { Mild exercise is one in which little force is applied (11) (8). }\end{array}$ \\
\hline & & $\begin{array}{l}\text { Riyazat-e-moatadil } \\
\text { Exercise that requires the utilization of moderate force. (11) (8). }\end{array}$ \\
\hline & According to sura'at & $\begin{array}{l}\text { Riyazat-e-sariya } \\
\text { The exercise in which quick and swift movements are required (11) (8). }\end{array}$ \\
\hline & & $\begin{array}{l}\text { Riyazat-e-batiya } \\
\text { Exercises in which the motions should be sluggish and staccato (11) (8). }\end{array}$ \\
\hline & & $\begin{array}{l}\text { Riyazat-e-moatadil } \\
\text { Movements in between riyazat sariya and batiya (11) (8). }\end{array}$ \\
\hline & $\begin{array}{l}\text { According to strength and } \\
\text { sura'at }\end{array}$ & $\begin{array}{l}\text { Riyazat-e-hasheesha } \\
\text { Movements that are both strong and rapid are carried out (11). }\end{array}$ \\
\hline & & $\begin{array}{l}\text { Riyazat-e-mutarakhiya } \\
\text { The movement is faint and sluggish in this situation (11). }\end{array}$ \\
\hline & & $\begin{array}{l}\text { Riyazat-e-moatadil } \\
\text { Exercise between hasheesha and mutarakhiya (11). }\end{array}$ \\
\hline
\end{tabular}




\section{Sharaite Riyazat/principles of exercise}

In the Sharaite Riyazat, eight principles are considered.

- The amount of physical activity. (8) (12)

- The timing of physical activity. (8) (12)

- $\quad$ Pre-exercise meal. (8)

- The age of the person who is performing Riyazat is taken into consideration. (8)

- The temperament of the individual performing Riyazat. (8)

- Physical characteristics of the individual doing Riyazat. (8)

- $\quad$ Present environment. (8)

- The physical condition of the bodily parts to be exercised. (8)

According to Hippocrates (Buqrat), one should avoid exercising or engaging in physical activity while hungry or on an empty stomach since it causes tiredness. As we all know, a person's health is determined by the foods he consumes, such as meat, chapatti, lentils, and rice (8). Because not all meals are completely digested, the undigested elements are discarded. And, while tabiyat removes waste, it does not eliminate it. As a result, reaming waste inside the body is harmful. If this waste material is putrified, it might cause infections (ufooni amraz) (13). When the Kayfiyt (quality) of retained matter changes, Sue Mizaj is created. Kammiyat (quantity) can sometimes grow, resulting in congestive illnesses (imtelai amraz). If they aggregate in an organ, they might induce inflammation (waram). Waste items can also modify the mizaj of rooh. Thus, exercise both avoids waste accumulation and aids in the disposal of waste from the body to preserve health (8) (11).

\section{MIQDARE RIYAZAT (QUANTITY OF EXERCISE)}

When it comes to exercise, Miqdare Riyazat refers to how much exercise should be done and when it should be ended (8). It should stop gradually. Three things should be kept in mind.

\section{Colour of the body}

Exercise should be continued until the skin's color remains radiant, and should be terminated if the skin's color turns dull or yellow ${ }^{(8)}$.

\section{Movements (Harkat) of the body}

When the body's movement is effortless, the exercise should be continued. If there is a sense of exhaustion, it should be discontinued. (8) (10) (14).

\section{3. (Aaza ka phoolna) Swelling of the organs.}

Exercise should be continued till the organs are swollen and sweating dried up and when the organs stop swelling and sweating continues, exercise should be stopped (8) (10).

\section{BENEFITS OF RIYAZAT (EXERCISE)}

- Regular and moderate physical exercise is necessary to reduce the risk of becoming ill and to maintain good health.

- Riyazat aids in the disintegration of morbid material and the removal of these matters from the body, among other things (8) (10) (15) (16).

- Riyazat organizes the body to gain nutrition (8) (11) (12) (14).
- It gives the body a sensation of lightness (8) (12).

- Appropriate activity activates the body's natural heat source (Hararate Gharizia) (8) (10) (9) (15) (16)

- Riyazat protects nerves, ligaments, cartilage, and joints by reinforcing them (11) (15).

- Riyazat fortifies the digestive ability (Quwate Hazma) and ability of evacuation (Quwate Dafia) (8) (15) (16).

- During Riyazat, the body's pores open, assisting in the natural evacuation of waste items from the body (8) (11) (15)

- Riyazat protects the body from ghair maddi and other maddi disorders. (8)

\section{Conclusion}

It has been seen in our culture that individuals are disinterested in exercising despite their knowledge of the beneficial roles of exercise in the prevention and control of several ailments. Numerous studies have demonstrated that exercise can also enhance immunity, self-esteem, mood, sleep quality, and energy levels while lowering the chance of developing a variety of ailments such as type 2 diabetes, hypertension, cardiovascular diseases, insomnia, depression, and dementia, among others. Given the rising incidence of lifestyle and non-communicable illnesses, healthcare providers should promote and prescribe exercise to patients who are at a higher risk of acquiring lifestyle disorders.

\section{Funding:}

None

\section{Declaration of competing interest:}

The authors declare that they have no known competing financial interests or the personal relations that could have seemed to affect the work reported in this paper.

\section{Acknowledgment:}

None

\section{References}

1. NHP A. Unani Medicine. ; 2016.

2. NHP A. Introduction of Regimental Therapy (Ilaj- biltadbeer). ; 2015.

3. Portal ANH. Riyaazat (Exercise); 2015.

4. Fatma, Nasir A, Siddiqui MJ, Wani. ROLE OF RIYAZAT (PHYSICAL EXERCISE) IN MAINTENANCE OF HEALTH MENTIONED IN UNANI MEDICINE. 2020; 9(5) 479-488.

5. Paffenbarger RS, Hyde RT, Wing AL, Hsieh CC. Physical activity, all-cause mortality, and longevity of college alumni. The new England Journal of Medicine. 1986; 314(10):605-13. https://doi.org/10.1056/NEJM198603063141003

6. Warburton, Nicol, Bredin. Health benefits of physical activity: the evidence Darren. The Canadian Medical Association Journal. 2006; 174(6):801-809. https://doi.org/10.1503/cmaj.051351

7. Firdaus, Sultana. RIYAZAT (EXERCISE): A PART OF ILAJ BIL TADBEER AND ITS ROLE IN THE PREVENTION OF 
DISEASES. International Journal of Development Research. 2016; 06(01):6486-6498.

8. Sina I. Kulliyat Qanoon New Delhi: Ejaz Publishing House; 2006.

9. Jurjani I. Zakhira Khawarazm Shahi New Delhi: Idara Kitabus Shifa ; 2010.

10. Baghdadi. Kitabul Mukhtarat Fit Tib. 1st ed. New Delhi: CCRUM; 2004.

11. Sina I. Al Qanoon Fit Tib. New Delhi: Idara Kitabus Shifa; 2010.
12. Nafis I. Kulliyat Nafisi New Delhi: Idara Kitab-u-Shifa; 1934.

13. Shah M. The Canon of Medicine by Avicenna. 23rd ed. Karachi: Naveed Clinic; 1998.

14. Razi A. Kitab ul Mansuri New Delhi: CCRUM; 1991.

15. Majoosi AIA. Kamilus Sana'ah New Delhi: CCRUM; 2010.

16. Rushd I. Kitab-ul-Kulliyat New Delhi: CCRUM, YNM. 